\title{
A INFLUÊNCIA DOS IDEAIS FRANCESES SOBRE AS DIRETRIZES EDUCACIONAIS BRASILEIRAS: CONCEPÇÕES, PRINCÍPIOS E TRAJETÓRIAS
}

\author{
The influence of french ideals on brazilian educational guidelines: \\ conceptions, principles and pathways
}

\section{La influencia de ideales franceses en las directrices educativas brasileñas: concepciones, principios y caminhos}

\author{
Caroline Delfino dos Santos* \\ Jacqueline de Cássia Pinheiro Lima* \\ Jurema Rosa Lopes Soares*
}

\section{Resumo}

Esse artigo tem como objetivo apresentar um recorte sobre os princípios que balizaram a construção da escola pública brasileira, norteando a elaboração das presentes legislações e diretrizes educacionais. A metodologia apoia-se nas contribuições da pesquisa bibliográfica com abordagem qualitativa, utilizando como fonte importantes legislações brasileiras e demais documentos legais. $O$ texto estrutura-se a partir da influência da educação francesa na construção do conceito de universalização do ensino. Em seguida, a pesquisa pauta-se sobre as trajetórias traçadas no processo de inclusão das camadas populares aos bancos escolares, citando como um importante movimento "Manifesto dos Pioneiros", 1932. Os estudos identificam importantes impactos da cultura educacional francesa sobre as legislações brasileiras, contudo foi observado um distanciamento ideológico entre as atuais políticas de inclusão das camadas populares na escola e os princípios de educação à luz dos intelectuais franceses. Assim, questionamo-nos sobre quais influências do pensamento francês ainda permanecem no cenário educacional brasileiro.

\footnotetext{
* Doutoranda e Mestre em Humanidades, Culturas e Artes pela UNIGRANRIO-Universidade do Grande Rio. Possui graduação em Pedagogia com habilitação em Orientação Educacional pela UNIGRANRIOUniversidade do Grande Rio. Especialização em Organização Curricular e Prática Docente na Educação Básica pela UERJ-Universidade do Estado do Rio de Janeiro. E.mail: carol.delfino.santos@gmail.com. Orcid: https://orcid.org/000-0002-5856-1973

* Pós-Doutorado em andamento no PPG em Cognição e Linguagem, na Universidade Estadual do Norte Fluminense Darcy Ribeiro - UENF. Pós Doutora pelo Programa de Pós-Graduação em História da Universidade do Estado do Rio de Janeiro. Doutora em Sociologia pelo Instituto Universitário de Pesquisas do Rio de Janeiro. Bacharel e Licenciada em História pela Universidade do Estado do Rio de Janeiro. Mestre em História Social da Cultura pela Pontifícia Universidade Católica do Rio de Janeiro. Email: jacapili.jl@gmail.com. Orcid: https://orcid.org/0000-0003-0982-6987

* Doutora em Educação pela Universidade Estadual de Campinas. Pesquisadora do Départament d'Ergologie-Université de Provence (França). Mestre em Educação pela Universidade do Estado do Rio de Janeiro. Graduada em Pedagogia pela Universidade Federal Fluminense. Professora/Pesquisadora da Escola de Ciências, Educação, Letras, Artes e Humanidades da UNIGRANRIO. Professora Permanente do Programa de Pós-Graduação em Humanidades, Culturas e Artes-UNIGRANRIO. Professora Colaboradora do Programa de Pós-Graduação em Ensino das Ciências- UNIGRANRIO. E-mail: jlopes@unigranrio.edu.br.
} 
PALAVRAS-CHAVE: História da Educação. Escola Pública. Universalização do Ensino.

\begin{abstract}
This article aims to present an outline on the principles that gave the base to the construction of the Brazilian public school, guiding the preparation of the present laws and educational guidelines. The methodology is based on the contributions of bibliographic research with a qualitative approach, using important Brazilian legislation and other legal documents as a source. The text is structured French education influence in the construction of the concept of universalization of teaching. Then, the research is based on the trajectories traced in the process of inclusion of the popular classes to the school benches, citing as an important movement "Manifesto dos Pioneiros", 1932. The studies identify important impacts of French educational culture on Brazilian legislation, but was observed an ideological distance between the current politics of the popular classes inclusion school and the principles of education according of French intellectuals. Thus, we question about the influences of French thought still remain in the Brazilian educational scenario.
\end{abstract}

KEYWORDS: History of Education. Public School. Universalization of Teaching.

\title{
Resumen
}

Este artículo tiene como objetivo demostrar un recorte sobre los principios que guiaron la construcción de la escuela pública brasileña, guiando la elaboración de la legislación y las directrices educativas actuales. La metodología está basada en las contribuciones de la investigación bibliográfica con enfoque cualitativo, utilizando como fuente la importante legislación brasileña y otros documentos legales. El texto está estructurado en función de la influencia de la educación francesa en la construcción del concepto de enseñanza universal. Luego, la investigación se guía por las trayectorias trazadas en el proceso de inclusión de los estratos populares a los bancos escolares, citando como un movimiento importante "Manifesto dos Pioneiros", 1932. Sin embargo, los estudios identifican importantes impactos de la cultura educativa francesa en la legislación brasileña. Se ha observado una brecha ideológica entre las políticas actuales de inclusión de las clases bajas en la escuela y los principios de la educación a la luz de los intelectuales franceses. Por lo tanto, nos preguntamos qué influencias del pensamiento francés aún vigorizan el escenario educativo brasileño.

PALABRAS CLAVE: Historia de la Educación. Escuela Pública. Universalización de la Enseñanza.

\section{INTRODUÇÃO}

O presente artigo busca identificar as principais mudanças sofridas pela educação brasileira no processo de formação da escola pública a qual as classes populares têm acesso hoje. Assim, para a compreensão da inserção das camadas mais pobres na escola, partimos da análise dos princípios que nortearam a educação pública francesa, bem como sua forte influência sobre a construção das diretrizes educacionais brasileiras. 
Para melhor elucidação dos dados históricos, nos apoiaremos em documentos e políticas púbicas que chamam a atenção da sociedade e governos para a importância da escolarização da população brasileira. Em estudo, identificamos que tais incentivos legais e demais documentos norteadores, por vezes, tiveram como objetivo capacitar tecnicamente mão de obra para o atendimento das demandas econômicas que emergiam em um país em vias de industrialização e urbanização.

No texto fazemos menção ao processo de democratização do ensino nos espaços destinados à oferta de educação pública, partindo da ideia que sustenta os princípios da universalização. Nesse contexto, recorremos à história para a compreensão das reinvindicações oriundas da Revolução Francesa, ainda no século XVIII. Dentre os principais apontamentos relacionados à educação, identificamos menções à necessidade de que a educação oferecida fosse essencialmente laica, além da luta para que ela passasse a ser oferecida de forma igualitária aos diferentes segmentos da sociedade.

Assim, iniciamos a primeira seção trazemos dados socioeconômicos que distinguem os países Brasil e França, mostrando que embora tenhamos importado elementos da ideologia político-educacional, outros aspectos interferem no alcance dos objetivos previstos. As questões de ordem cultural, bem como fatores de ordem espacial, vão nos revelar que ambos os países experenciavam contextos de desenvolvimento distintos. Salientamos ainda que a desigualdade social presente em larga escala no Brasil interfere sobremaneira no processo educacional.

Para uma maior compreensão a respeito dos princípios que nortearam a concepção de educação na Franca, fazemos menção a dois importantes nomes: Rousseau e Condorcet. O primeiro, filósofo iluminista, dedica-se a pensar o ensino a partir de um olhar sobre as faculdades da criança, trazendo uma mudança de paradigmas sobre a forma com devem ser educadas, desde seu nascimento. Para Rousseau, o homem nasce bom, sendo corrompido pelo seu entorno. Segundo o filósofo, para se pensar em um modelo de cidadão ideal seria preciso dedicar-se à sua formação desde a mais tenra idade.

O Marques de Condorcet, Marie Jean Antoine Nicolas de Caritat, por sua vez, destacou-se por defender que a educação voltada à formação cidadã compete ao Estado, devendo ser oferecida de forma laica e igualitária. De acordo com tal princípio, a formação religiosa competia aos sacerdotes e demais líderes, devendo ser ministrada em seus respectivos templos.

Embora a Constituição Brasileira (Brasil, 1988) se apresente como destituída de princípios religiosos, adotando, portanto, o sentido de um Estado laico, vimos, no Congresso Nacional, ser instituída uma bancada reconhecida como sendo evangélica. Ademais, especificamente no campo da educação, o currículo escolar tem em sua grade o ensino religioso como uma das disciplinas a ser ministrada ainda que sob a forma de matrícula facultativa (BRASIL, 1996)

No que se refere ao processo de universalização do ensino no Brasil, na segunda seção fazemos alusão às contribuições do "Manifesto dos Pioneiros" (1932), reconhecendo-o como um importante movimento a favor da educação das minorias, tendo sido proveniente do debate entre grandes intelectuais da época. Ressaltamos, contudo, que o contexto político vivenciado pelo país na década de 1930 inclinava-se para a modernização e desenvolvimento econômico, ansiando deixar para trás características de um país predominantemente rural. Para tal, fazia-se necessário o aumento do nível de escolaridade da população, mais especificamente, a formação de 
trabalhadores capacitados para atender as expectativas decorrentes do processo de industrialização. Não por acaso, na década subsequente, são implementadas duas importantes instituições de ensino profissionalizante: SENAI-Serviço Nacional de Aprendizagem Industrial (Brasil, 1942) e SENAC- Serviço Nacional de Aprendizagem Comercial (Brasil, 1946), criadas através da Reforma Capanema.

Considerando as estatísticas de baixa escolaridade da população da época, o Brasil, a exemplo de outros países, adota políticas que visam uma maior inclusão da população nas escolas, recorrendo à legislações e documentos oficiais para o alcance de metas. Acordos com referências internacionais também são firmados, garantindo a aquisição de empréstimos com vistas ao seu desenvolvimento.

As desigualdades de cunho socioeducacionais no Brasil, bem como a busca pela universalização do ensino traz as diretrizes para a construção da terceira seção do presente artigo. Por fim, os estudos realizados apontam ainda para o reconhecimento de avanços no campo da educação no que se refere a inserção das camadas mais populares na escola, tal como previsto pelos idealizadores do ensino gratuito. A influência do pensamento francês na promulgação das legislações educacionais contribuiu para a busca da universalização do ensino, contudo, o desejo pela modernização do país, vinculado à interesses internacionais contemporâneos, não coadunam com os princípios formulados pelos ideais da Revolução Francesa.

\section{Notas sobre educação pública francesa e seu impacto sobre a educação brasileira: diálogos e divórcios}

A França, país localizado no continente europeu com 64 milhões de habitantes, apresenta o sexto maior PIB do globo, posição essa mantida nos últimos três anos. Tal classificação reflete no IDH-Índice de Desenvolvimento Humano da população avaliado em 0,891, colocando-a em $26^{\circ}$ lugar no ranking mundial, de acordo com Panorama general Informe sobre Desarrollo Humano 2019 Más allá del ingreso, más allá de los promedios, más allá del presente: Desigualdades del desarrollo humano en el siglo XXI divulgado em 2019. De acordo com dados divulgados pelo Relatório de Desenvolvimento Humano de 2014 a expectativa de vida é de 81,8 anos. Em termos de educação, a média de escolaridade é de 11,1 anos, apesar de a expectativa seja de 16 anos. Em 2013 a ONU afirma que a cada mil crianças que nascem no país, apenas 4 óbitos são registrados e praticamente todos habitantes com idade superior a 15 anos são alfabetizados. Em contrapartida, o Brasil, com 200 milhões de habitantes, encontra-se em $79^{\circ}$ lugar, com IDH referente a 0,761 , junto à Colômbia. A expectativa de vida gira em torno de 73,9 anos.

Os dados comparativos salientam que, apesar de o Brasil buscar inspirações nos aspectos ideológicos e filosóficos da França para a construção da sua educação, não necessariamente vai refletir a mesma qualidade de vida para a população, muito em função das desigualdades presentes no país.

As desigualdades de ordem econômica interferem diretamente no processo educacional. A história da educação formal no Brasil não revela a inclusão das camadas mais pobres da sociedade e tal dado perdura por longo período de tempo.

Com vistas a um melhor entendimento dessa realidade socioeconômica, nos apoiaremos ainda nos estudos a respeito da pobreza, desigualdade e exclusão social, 
abordando ainda a educação como um direito social, conforme previstos nas legislações citadas.

Historicamente a educação francesa atuou como inspiração para a construção da educação pública no Brasil. A origem da escola brasileira entrelaça-se aos movimentos iniciais que ocorreram na França, nação que desde os últimos séculos influenciou a cultura e legislações educacionais brasileiras. Em tempo, cumpre destacar a importância dos enfoques de Rousseau na formação das crianças, "tal como os contornos do discurso educacional efetuado durante a Revolução Francesa.” (BOTO, 1996, p.16).

Nascido em Genebra no ano de 1712, Rousseau viveu boa parte da vida em Paris. Filósofo do Iluminismo (movimento que inspirou a Revolução Francesa) viveu à frente do seu tempo e tal como um grupo de políticos e médicos posiciona a criança no centro do processo educacional. Boto (1996) nos traz algumas críticas tecidas por Rousseau acerca da educação oferecida às crianças com o propósito de capacitá-las para a vida em sociedade: "Que se pode pensar dessa educação bárbara que sacrifica o presente a um futuro incerto, que aprisiona a criança e principia por torná-la miserável, para prepará-la a distância para sabe-se lá qual felicidade, de que provavelmente ela jamais desfrutará?" (ROUSSEAU apud BOTO, 1996, p. 26).

Rousseau apresenta em Emílio, uma mostra da sua percepção sobre como a criança deve ser educada e constrói argumentos sobre como a escola corrompe o homem, apropriando-se de sua liberdade. Tais argumentos justificam-se em razão de ter passado boa parte da infância sob rigorosa educação religiosa.

\begin{abstract}
Nascemos fracos, precisamos de força; nascemos carentes de tudo, precisamos de assistência; nascemos estúpidos, precisamos de juízo. Tudo o que não temos ao nascer e do que precisamos quando grandes nos é dado pela educação. Essa educação vem-nos da natureza ou dos homens ou das coisas. O desenvolvimento interno de nossas faculdades e de nossos órgãos é a educação da natureza; o uso que nos ensinam a fazer deste desenvolvimento é a educação dos homens; e a aquisição de nossa própria experiência sobre os objetos que nos afetam é a educação das coisas. (ROUSSEAU, 1995, p. 1011).
\end{abstract}

Ao afirmar que a natureza do homem ao nascer é frágil, Rousseau compreende que é por meio da educação que conseguimos superar tais limitações, assim como defende que é por meio dela que nos capacitamos para o uso das nossas faculdades. Embora desenvolva tal reflexão, segue apresentando ponderações à forma de controle social impressas no educar do século XVIII.

Comumente abordamos a democratização da escola pública como tema central visando a universalização do processo educacional. Tal apontamento surge como uma das grandes reivindicações da Revolução Francesa ao fim do século XVIII. A Revolução traz consigo, em seus ideais, o desejo de que o ensino fosse ministrado em instituição pública e de maneira laica. Junto ao povo, a burguesia reivindica igualdade de oportunidades educacionais, potencializando assim a ideia da universalização do ensino.

Os fins educacionais propostos pelos intelectuais da época consistiam em formar uma sociedade de fato democrática, para tal, a escolarização foi pensada como uma das principais ferramentas na construção da nacionalidade e regeneração da pátria. Para o alcance dos objetivos traçadas, foi de suma importância a atuação de Marie-Jean- 
Antoine-Nicolas Caritat, o Marquês de Condorcet a partir da construção do Relatório de Condorcet.

Oriundo de família nobre Condorcet inicia sua vida escolar no Colégio de Jesuítas, seguindo seus estudos em Filosofia no Colégio de Navarras, em Paris. Destacou-se pelo domínio da Matemática, chegando a ser considerado pioneiro da Matemática Social, elevando-o posteriormente ao status de enciclopedista. Tais conhecimentos não o caracterizavam como um filósofo, embora tenha construído uma relação estreita com intelectuais renomados como Voltaire, Diderot, D'Alembert e outros grandes pensadores da época. Também participou da Academia de Ciências, junto a outros integrantes do movimento enciclopedista, sendo especialmente reconhecido por sua preocupação com pobres marginalizados.

A dedicação de Nicolas de Condorcet à Matemática e sua forte inclinação aos estudos da sociedade o conduziram a construir a ideia de revisão constitucional, uma vez que defendia que as legislações precisavam ser constantemente submetidas ao jugo com vistas ao seu aperfeiçoamento e melhor atendimento ao povo.

Condorcet acreditava que para o alcance da democracia, necessário era a soberania do homem sobre a ciência e a razão e só por meio da oferta universal da educação, o apreço à igualdade e à liberdade (dois dos três lemas da Revolução Francesa) seria amplamente desenvolvido. A partir dessa ótica, a instrução formal oferecida pela escola pública seria um importante recurso para a promoção da igualdade social e formação da consciência livre. Condorcet e outros intelectuais almejavam romper com a ideia de acumulação de bens por meio da hereditariedade, propondo o mérito pessoal como critério para equalização das oportunidades:

Quando Condorcet é nomeado presidente do Comitê de Instrução Pública da
Assembleia Legislativa Francesa, ele percebe ali a oportunidade de elaborar
um traçado de escolarização capaz de, por um lado, fazer justiça para as
camadas menos privilegiadas da população, e ser, ao mesmo tempo,
racionalmente projetado. Isso conduziria, progressivamente, à equalização
das oportunidades de acesso à escola, e, por decorrência, a uma diminuição,
na ordem social, de clivagens postas pela desigualdade de fortunas. (BOTO,
2003, s/p).

Embora a Assembleia Legislativa projete o intitulado "Plano de Instrução Nacional" no ano de 1792, este não alcança grande notoriedade naquele momento. Apenas no século seguinte recebe maior visibilidade no continente europeu e posteriormente na América Latina, mais especificamente em terras brasileiras. Os pressupostos que delinearam a educação pública na França por meio da organização de projetos e diretrizes impulsionaram grandes reformas promovidas nos séculos XVIII e XIX.

Os delineamentos atribuídos à educação por meio dos princípios da Revolução Francesa atuam como referência pedagógica para a construção das legislações brasileiras vigentes. Esse modelo de escola pública, gratuita e laica, constitui-se como herança do pensamento que se construiu junto à Revolução, trata-se, pois, da base histórico-social da educação brasileira.

A França, por assim dizer, representa nossa matriz educacional, espaço onde foi gerada a ideia de escola pública para todos. Nasce então não apenas a defesa incisiva pelo ensino democrático, como também a defesa pela escola pública, gratuita e universal, princípios estes, não por acaso, presentes na Constituição Federal Brasileira. 
A Lei de Diretrizes e Bases da Educação Nacional nº 9394/96 não faz menção ao ensino laico, contudo, a Lei Magna institui o Estado como sendo laico, ou seja, o país deve manter-se isento das questões religiosas no que se refere às suas tomadas de decisão. A religiosidade do indivíduo não compete ao Estado, mas sim às organizações específicas e inerentes de cada religião.

Ainda em solos brasileiros, embora a religião não devesse interferir nos assuntos que competem ao Estado, em 2015, a Frente Parlamentar (identificada como) Evangélica era composta por 199 (Cento e noventa e nove) deputados e 4 (Quatro) senadores de diferentes partidos. A composição de uma bancada com perfil confessional intensifica questionamentos em relação à laicidade prevista pelo Estado. A plataforma política apresentada pela bancada vai de encontro à ideologia religiosa de seus membros, comprometendo decisões que deveriam contemplar as demandas de toda sociedade.

No campo da educação, contrariando a Lei Magna, a LDB 9394/96 em seu artigo 33 determina:

\begin{abstract}
O ensino religioso, de matrícula facultativa, é parte integrante da formação básica do cidadão e constitui disciplina dos horários normais das escolas públicas de ensino fundamental, assegurado o respeito à diversidade cultural religiosa do Brasil, vedadas quaisquer formas de proselitismo. $\S 1^{\circ}$ Os sistemas de ensino regulamentarão os procedimentos para a definição dos conteúdos do ensino religioso e estabelecerão as normas para a habilitação e admissão dos professores. $\S 2^{\circ}$ Os sistemas de ensino ouvirão entidade civil, constituída pelas diferentes denominações religiosas, para a definição dos conteúdos do ensino religioso. (BRASIL, 1996).
\end{abstract}

A implementação e prática do ensino religioso nas escolas públicas não só põe em xeque o caráter laico do Estado como legitima algumas religiões em detrimento de outras, visto que nem todas são contempladas no espaço educacional. Diante do exposto, é questionável se de fato é assegurado o respeito à diversidade cultural religiosa do Brasil, como prescrito na lei (BRASIL, 1988).

A relação entre educação e religião é de longa data. Se sob a Influência dos propósitos da Revolução Francesa o Brasil pauta suas leis educacionais com base nos princípios da França do século XVIII, cumpre lembrar que, enquanto colônia portuguesa, vivia sob a orientação da Companhia de Jesus. O país sofria grande intervenção da metrópole lusitana, ministrando um ensino catequético só interrompido a partir da expulsão dos Jesuítas no ano de 1759, por meio da Reforma Pombalina, sob os argumentos da corrente iluminista. Tal reforma, liderada por Marques de Pombal tinha por objetivo diminuir a atuação da Igreja, visto que esta representava riscos à ordem e ao poder do Estado.

Os ideais franceses sobre a ministração de um ensino pautado na laicidade parecem não se consolidar em nossas legislações educacionais e o ingresso da população pobre nas escolas percorre um longo caminho até que alcancemos a universalização do ensino. Nesse processo, entra em debate as atribuições do Estado e da família no que se refere à educação das crianças. Assim, a próxima seção aborda o ingresso das camadas mais pobres nas unidades de ensino, tendo o Manifesto Pioneiro como um importante marco nesse processo.

\title{
A importância do Manifesto dos Pioneiros no cenário educacional brasileiro
}


A década de 1930, no que tange os contornos dados à educação, compreende um período marcado pela forte influência de um grupo de intelectuais que, muito embora fizesse parte de uma elite, uniram-se para a produção e assinatura de um manifesto que favoreceria a inserção das crianças pobres na escola. No ano de 1932, nomes como Cecília Meireles, Anísio Teixeira, Lourenço Filho, Armanda Álvaro Alberto e Fernando Azevedo imprimiram suas assinaturas no documento intitulado Manifesto dos Pioneiros da Educação, tendo como subtítulo A reconstrução educacional no Brasil: ao povo e ao governo. Cumpre mencionar que em meados da década de 1920, por meio da ABEAssociação Brasileira de Educação, tais pioneiros já vinham se organizando e repensando os rumos da educação no país.

Patto (1999) considera os episódios históricos das décadas de 1920 e 1930 como importantes passos rumo à educação popular:

\begin{abstract}
Embora tenha sido apenas a partir dos anos trinta que o crescimento da rede pública de ensino tornou-se realidade (os historiadores da educação do Brasil concordam que até 1930 não dispúnhamos de um sistema de educação popular), não se pode esquecer que sua construção se dá sob a nítida influência das ideias e lutas encaminhadas nos dez anos anteriores. Por isso, a década de vinte é o vestíbulo da década de trinta e a compreensão das ideias educacionais em vigor a partir de então não pode prescindir do mapeamento das ideias que a precederam. (PATTO, 1999, p. 84).
\end{abstract}

Patto (1999) nos chama a atenção para a seguinte conduta do Estado: "O Estado desincumbiu-se do ensino primário e voltou-se principalmente para o ensino secundário e superior, garantindo aos mais ricos o diploma como passaporte para os mais altos níveis públicos." (PATTO, 1999, p. 79) Assim, o manifesto configurou-se como importante documento do início do século XX por reunir os aspectos obrigatório, laico e gratuito, prevendo a oferta de todo o ensino fundamental e depositando no Estado essa responsabilidade.

O manifesto apresenta preocupações com os rumos que a educação tomaria e reivindicava a construção de um plano nacional, visto que os países ao entorno já apresentavam avanços em relação a esse aspecto. $\mathrm{O}$ documento tomou proporções nacionais por meio de jornais e, posteriormente, com a publicação de um livro, cujo conteúdo defendia a ideia de uma educação comum a todos. Os pioneiros não só defendiam a igualdade na oferta do ensino como também acreditavam que a educação seria capaz de promover o desenvolvimento econômico e social. Tal concepção perdura até os dias de hoje quando se discute a relação entre desigualdade social e pobreza.

O Manifesto dos Pioneiros acreditava que a obrigatoriedade do ensino instituída pelo Estado não poderia estar desvinculada do quesito gratuidade, por saber que a maioria da população por recursos próprios não conseguiria alcançar os bancos escolares:

A gratuidade extensiva a todas as instituições oficiais de educação é um princípio igualitário que torna a educação, em qualquer de seus graus, acessível não a uma minoria, por um privilégio econômico, mas a todos os cidadãos que tenham vontade e estejam em condições de recebê-la. (MANIFESTO DOS PIONEIROS, 1932). 
Mesmo defendendo que o Estado deveria garantir de forma gratuita a oferta do ensino, os intelectuais que assinaram o documento tinham a ciência das limitações de seus ideais, uma vez que o número de escolas não atenderia a demanda da população em idade escolar naquele dado momento. A perspectiva promovida em 1930 possibilitaria a inclusão de crianças pobres na escola, contudo, não garantia a oferta do ensino com a devida qualidade.

O debate promovido através da divulgação do manifesto trazia à tona a educação como um grande problema de ordem social e emergencial. Os contornos dados ao tema colocavam-no em evidência, chamando atenção para a necessidade de uma reformulação dos ideais acerca da educação, ou melhor, uma organização do sistema escolar de forma a atender mais democraticamente as diferentes classes existentes no país: A construção de Plano Nacional de Educação.

A opção por mencionarmos alguns dos ideais presentes no Manifesto dos Pioneiros justifica-se por este reunir elementos condizentes com a promoção da democratização do ensino, apresentando com isso um olhar especial às camadas mais pobres da sociedade.

Ampliando o rol de literaturas em relação ao movimento, outros autores por meio de suas construções teóricas vão apresentando mais claramente ideais também embutidos nos princípios presentes no documento:

\begin{abstract}
Economicamente, objetivavam substituir uma economia agrária pela produção industrial e pelo trabalho livre e assalariado. Lutavam pela ampliação das indústrias para atingir um desenvolvimento industrial desejável. Politicamente lutavam pela expansão da escola pública, que era entendida como responsável pela formação do trabalhador. Alfabetizar era sinônimo de preparar para a cidadania, para o voto, era preciso formar mão de obra nacional especializada. (IVASHITA e VIEIRA, 2009, p. 6).
\end{abstract}

Embora houvesse uma intenção de cunho social em alfabetizar a população pobre através do princípio da educação para todos, outras intenções de cunho políticoeconômico motivavam uma ampla reforma do ensino. O Brasil vinha passando por um processo de urbanização e as perspectivas educacionais à época não coadunavam com um país em vias de desenvolvimento. Um país com perfil moderno-industrial implicaria no aprimoramento da educação da população visando qualificá-la para o aperfeiçoamento profissional.

O manifesto incorre em críticas apontadas por Patto em razão de suas finalidades associarem-se a aspectos de ordem biológica, tornando-o dúbio:

A defesa do direito extensivo a todos os cidadãos de educarem-se até onde o permitissem suas aptidões naturais, independente de razões de ordem econômica e social, corria paralelamente a defesa das escolas profissionalizantes- predominantemente manuais - para as massas rurais e o elemento trabalhador da cidade e dos centros industriais. (PATTO, 1999, p.133).

Identificamos ainda outra intenção repudiada por Patto (1999), o da seleção de funções por meio das questões econômicas e sociais, diferente do que prevê o documento: 


\begin{abstract}
As justificativas para esta atribuição são pouco claras: fala-se em satisfazer necessidades práticas de adaptação à variedade dos grupos sociais. Não fica sugerido, em qualquer passagem, que os integrantes das classes trabalhadoras seriam menos aptos à progressão nos estudos ou a cursos predominantemente intelectuais. Mas talvez, esse pressuposto já estivesse presente no caráter tautológico da justificativa de uma escola profissionalizante para as classes trabalhadoras. (PATTO, 1999, p. 133).
\end{abstract}

A escola funcionaria, ainda que de forma velada, como um aparelho de estratificação social oferecendo ensino profissionalizante às massas com vistas ao desenvolvimento do país, enquanto à outra parcela da sociedade era destinado o ensino voltado para o desenvolvimento do intelecto.

A despeito da visão economicista que pairou sobre a escolarização das camadas pobres, não é possível desconstruir as benéfices propostas pelo documento. Em linhas gerais, o manifesto revelou um olhar social sobre a educação, entendendo-a como um problema e alinhavando soluções para ele. Pensar na oferta do ensino de forma a abarcar o maior contingente populacional na idade escolar prevista na época ( 7 a 15 anos) configurou-se como um importante ato no caminho para a universalização do ensino. O desejo por um ensino laico, gratuito e obrigatório levava a educação a novos patamares instituindo ao Estado sua ampla oferta. De fato, o manifesto pode ser considerado um importante feito para a história do ensino público no Brasil.

Mais recentemente, vimos o ingresso das crianças à escola ser reconhecido pelo viés legislativo. $\mathrm{O}$ reconhecimento da necessidade de que as crianças ingressem na escola aos quatro anos configura-se como um importante passo na educação. De acordo com a LDB n ${ }^{\circ}$ 9394/96, em seu artigo $4^{\circ}$ :

\begin{abstract}
O dever do Estado com educação escolar pública será efetivado mediante a garantia de: I - educação básica obrigatória e gratuita dos 4 aos 17 anos de idade, organizada da seguinte forma: a) pré-escola; b) ensino fundamental; c) ensino médio; II - educação infantil gratuita às crianças de até 5 anos de idade; (BRASIL,1996, S/P)
\end{abstract}

Com a inserção da obrigatoriedade na oferta de ensino público a partir da idade de quatro anos em 2013 através da Lei 12.796, identificamos não apenas a ampliação da escolaridade, como principalmente o reconhecimento da importância da Educação Infantil no desenvolvimento dessas crianças. Tal mudança, favorece em especial as crianças oriundas das camadas sociais pobres, uma vez que os filhos das categorias mais favorecidas financeiramente são, desde muito cedo, inseridos nas creches e pré-escolas da rede privada de ensino.

\title{
Desigualdades socioeducacionais e a busca pela universalização do ensino no Brasil
}

A baixa escolarização não é fator determinante para ser pobre, entretanto por meio das estatísticas há de se identificar que ela é uma marca predominante em meio à população. Assim, a escola ainda é compreendida como um trampolim capaz de promover a mobilidade social. Visto dessa maneira, a ascenção ainda perpassa pelos muros da escola. 
Entendo a gravidade da desigualdade presente no acesso dos grupos mais pobres à escolarização brasileira, bem como aos demais grupos marginalizados na/pela sociedade o PNE (Plano Nacional de Educação) estabelece como oitava meta a ampliação da escolaridade da população. Tal meta apresenta como público alvo pessoas entre 18 (dezoito) e 29 (vinte e nove) anos de idade, desconsiderando quaisquer etapas de ensino. O objetivo consiste em elevar os anos de escolaridade das pessoas residentes no campo e da população com renda familiar per capita entre os $25 \%$ mais pobres do país, além de equalizar a escolaridade média entre negros e não negros declarados ao IBGE.

Até o ano de $2014,25 \%$ da população mais pobre vivia com valor inferior a $\mathrm{R} \$ 414,00$ por membro de cada família, enquanto que os $25 \%$ mais ricos viviam com, no mínimo, R\$1.312,00. Em análise ao Índice de Gini ${ }^{1}$, pudemos identificar que o Brasil apresenta o valor de 0,518, um dos piores índices mensurados no globo.

A meta 8 (oito) considera não apenas a urgência em aumentarmos a escolarização dos grupos mais vulneráveis, como também entende que essa ampliação poderá ser capaz de diminuir a distância econômica entre os mais ricos e os mais pobres da sociedade.

De acordo com dados coletados pelo PNAD (Pesquisa Nacional por Amostra de Domicílios) em 2014, o atual quadro de escolarização no Brasil, tendo como base o público apesentado, consiste em 8,3 anos, enquanto a meta estabelecida é de 12 anos até o ano de 2024, ano em que o plano em vigor se encerra. O número representativo da escolaridade dos $25 \%$ mais pobres do país encontra-se mais baixo até mesmo da população com a menor escolaridade avaliada por região, que é a região Nordeste, com uma média de 9,1 anos.

A escolha pelos doze anos estabelecidos como meta leva em consideração que cada pessoa possa ter acesso no mínimo ao ensino fundamental ( 9 anos) e o ensino médio (3 anos). Importante considerar que as estatísticas já apresentaram dados ainda mais alarmantes. No ano de 2001, a média da escolaridade dos $25 \%$ mais pobres era de apenas 5,1 anos.

Em 1990, a Tailândia era palco de uma Conferência Mundial sobre Educação que resultou na elaboração da Declaração Mundial sobre Educação para Todos, ou como é mais conhecida, Declaração de Jomtien. 0 documento manifesta a preocupação com o fato de milhões de pessoas não terem acesso à educação, na época, ou não a ter de forma satisfatória. Com base nos dados apresentados anteriormente o quadro social brasileiro corroborava para as estatísticas em nível global:

Mais de 100 milhões de crianças, das quais pelo menos 60 milhões são meninas, não têm acesso ao ensino primário; mais de 960 milhões de adultos - dois terços dos quais mulheres são analfabetos, e o analfabetismo funcional é um problema significativo em todos os países industrializados ou em

\footnotetext{
${ }^{1}$ Instrumento elaborado pelo matemático italiano Conrado Gini no início do século XX com o objetivo de identificar o nível de desigualdade econômica presente em um país. O Índice de Gini é calculado pelo IPEA- Instituto de Pesquisa Econômica Aplicada a partir de dados apresentados pelo PNAD- Pesquisa Nacional por Amostra de Domicílios. Consiste em uma medida da desigualdade de renda que evidencia a diferença entre os rendimentos das pessoas mais pobres e das mais ricos. Apresenta variação entre 0 evidenciando um país igualitário e 1 sinaliza grande concentração de renda por um restrito grupo de pessoas.
} 
desenvolvimento; mais de um terço dos adultos do mundo não têm acesso ao conhecimento impresso, às novas habilidades e tecnologias, que poderiam melhorar a qualidade de vida e ajudá-los a perceber e a adaptar-se às mudanças sociais e culturais; e mais de 100 milhões de crianças e incontáveis adultos não conseguem concluir o ciclo básico, e outros milhões, apesar de concluí-lo, não conseguem adquirir conhecimentos e habilidades essenciais. (UNESCO, 1990, S/P).

Importante pensarmos que os grupos mais vulneráveis ao estigma da pobreza hoje compõem a escola pública. Concomitante ao período da Declaração de Jomtien, Milet (1990) buscava refletir sobre o perfil socioeconômico dos alunos da escola pública brasileira, oriundos das classes populares, optando por apresentar estatísticas que revelavam um país marcado pela desigualdade:

Brasil, década de 1990, final do século XX, 140 milhões de habitantes. Dos 4 milhões de crianças que nascem por ano, cerca de 300 mil morrem antes de completar um ano. As altas taxas de mortalidade infantil são causadas por doenças de fácil prevenção que estão associadas a fatores de risco de caráter sócio econômico e ambiental: (...) O saneamento básico é um dos fatores fundamentais na determinação das condições de saúde da população brasileira, especialmente nos índices de mortalidade infantil. Em 1984, apenas $46,1 \%$ dos domicílios no Brasil tinham rede de esgoto adequada. Outro fator que exerce grande influência nos índices de mortalidade infantil é o nível de instrução da mãe. Em 1986, enquanto a mortalidade infantil para as crianças de mães sem instrução era de 100,5 óbitos por 1000 nascidos vivos, a mortalidade daqueles cujas mães tinham mais de 5 anos de instrução caía para 40,1 por 1000. (MILET, 1990, p. 6).

Como prática inerente à função de orientadora educacional, cotidianamente ouvia os problemas vivenciados por alunos do Complexo de Favelas da Maré/RJ, bem como seus familiares. Diante da experiência, Milet buscou desenvolver uma análise da realidade macro do país, que não estava desconectada da realidade local:

Em matéria de distribuição de renda, o Brasil é praticamente o campeão de desigualdade, só perdendo para Serra Leoa, paupérrimo país africano e para Honduras, pequena república da América Central. Somente $1 \%$ da população detém a renda correspondente a $50 \%$ da população. Os números mostram que o Brasil é um país pobre em todas as áreas. Sem saúde, sem educação, onde $20 \%$ dos chefes de família são mulheres desassistidas e $23 \%$ da população que trabalha ganham menos de um quarto do salário mínimo. (...) (MILET, 1990, p. 7-8)

Seguindo o debate sobre a política de educação para todos, em 1993 nova conferência mundial é instituída, dessa vez em Nova Delhi, Indía, e dentre as metas elencadas, chamamos a atenção para a redação das metas de número 1(um), 3(três): 1) Elevar a 94\% a cobertura da população em idade escolar; 3) Melhorar o fluxo escolar, reduzindo as repetências, de maneira que $80 \%$ dos alunos concluam o ensino fundamental com bom aproveitamento; (UNESCO, 1993, S/P)

Em 2015 o Banco Mundial anuncia duplicação de financiamentos, chegando ao total de US\$ 5 bilhões nos cinco anos subsequentes com vistas a erradicação da pobreza no mundo. $\mathrm{O}$ financiamento estará atrelado aos resultados inerentes à educação. De acordo com informações apresentadas pelo próprio Banco, o objetivo supera a 
expectativa da universalização do ensino, e intenta assegurar que as crianças tenham acesso a conhecimentos relacionados à leitura e matemática como possibilidade de adquirirem meios para a superação da miserabilidade.

O Banco Mundial se auto declara como o maior financiador da educação em todo o globo, tendo investido nas duas últimas décadas aproximadamente US\$ 40 bilhões neste setor por meio de empréstimos e parcerias diversas. Como bem se vê, a concessão de recursos está diretamente atrelada à intervenção do banco não apenas por meio de um acompanhamento minucioso dos planos de ação, como através do próprio direcionamento de diretrizes e imposições de metas.

Conforme previsto na Conferência de Nova Délhi, os índices de evasão diminuíram e, por meio de medidas discutíveis, as crianças apresentam também menores índices de retenção. Diante da chamada promoção automática, questionamonos com que qualidade essas crianças e jovens passam pela escola. A universalização do ensino obriga-nos a pensar em como atender com qualidade a clientela pobre que hoje encontra-se na escola pública.

As Diretrizes Curriculares Nacionais para Educação Básica (BRASIL, 2013) consideram que o acesso e permanência das crianças e jovens à/na escola consistem em importantes estratégias para a conquista da qualidade social. De acordo com o documento, os aspectos quantitativos na educação vêm se sobrepondo em relação à qualidade e aponta como crítica central que a universalização do acesso à escola é uma medida necessária, mas que não assegura a permanência, essencial para compor a qualidade (BRASIL, 2013, p. 24). Categoricamente, chama-nos a atenção para a importância de a oferta de vagas estar intrinsicamente vinculada à ideia de qualidade pedagógica, política e social, devendo ainda estar comprometida em garantir a permanência de crianças e jovens na escola.

Com vistas à continuidade de concessão de empréstimos e não especificamente com interesse sobre o desenvolvimento educacional dos alunos, o país vem traçando estratégias de superação para o problema da baixa escolaridade da população. No corpo das Diretrizes Curriculares Nacionais para Educação Básica (BRASIL, 2013) é possível observar a sistematização do que a Lei 9394/96 prevê como ações essenciais para a promoção do acesso e permanência das crianças e adolescentes na escola, revelando que ambos os documentos oficiais dialogam entre si: "quanto à família, os pais ou responsáveis são obrigados a matricular a criança no Ensino Fundamental, a partir dos 6 anos de idade." (BRASIL, 2013)

\section{CONSIDERAÇÕES FINAIS}

A cultura francesa impacta países de diferentes pontos do globo e o Brasil se insere nessa lista. Marcos da história nos revelam que a presença do pensamento francês impacta diferentes setores da nossa forma de organização, não apenas no que se refere à cultura, mas no campo da filosofia e das artes. Nesse artigo, em especial, propomos uma análise sobre a influência dos princípios franceses no processo de formulação das legislações que regem a educação brasileira.

Para inaugurarmos tais reflexões no presente artigo, partimos das contribuições de Rousseau a respeito de uma nova forma de se pensar a formação do cidadão, via educação da criança desde a primeira infância. Em seguida, elucidamos defesas 
apresentadas por Condorcet em torno da oferta do ensino laico, bem como formação igualitária, incluindo as classes menos favorecidas.

Tais princípios contribuem para a ideia de educação pensada e prevista em importantes legislações brasileiras, tendo influenciado movimentos de grandes proporções nacionais. O Manifesto dos Pioneiros apresenta-se como uma importante posição oriunda de uma elite intelectualizada que previa, sobretudo, o ensino obrigatório, laico e gratuito. Um importante passo para a reconfiguração do quadro instaurado no país: Uma população, em sua maioria, de analfabetos.

Apesar da promulgação de leis a favor da escolarização da população, observamos que o contexto político do país, atrelado ao forte desejo por sua industrialização, foi um motivador para que os mais pobres tivessem acesso à escola, concentrando-se na preparação de mão de obra. Uma leitura sobre o panorama contemporâneo que rege os princípios balizadores da oferta de ensino nos permite identificar uma estreita relação entre as metas previstas nos documentos educacionais e as expectativas das organizações internacionais que financiam, via empréstimos, a educação do país.

Assim, concluímos que os destaques atribuídos à França, seus ideais de direitos humanos e revolucionários, bem como sua visão crítica sobre a política, por vezes, estiveram presentes nas bases da educação brasileira. Entretanto, a estreita relação entre algumas metas previstas nos planos de educação e metas provenientes de órgãos privados internacionais, nos permite identificar um divórcio entre os princípios franceses e os contornos dados à oferta do ensino, condicionada ao ideal de ampliação da escolaridade da população, com poucas exigências quanto à qualidade com que crianças e jovens são mantidos nos espaços escolares.

Tal como o cenário econômico e político do país, a educação em sua essência é marcada por múltiplas desigualdades presentes no currículo escolar que insiste em ignorar o histórico e contexto social dos alunos pobres. A inserção das crianças pobres na escola pública não se relaciona apenas à ampliação da escolaridade da população. Para além dos dados estatísticos, ela requer que a inclusão das massas esteja alinhada a um projeto de educação inclinado, sobretudo, à amenização das desigualdades.

\section{REFERÊNCIAS}

ARANHA, Maria Lúcia de Arruda. História da Educação. São Paulo: Moderna, 2006.

BOTO, Carlota. A escola do homem novo: entre o Iluminismo e a Revolução Francesa. São Paulo: Editora UNESP, 1996.

Na revolução francesa, os princípios democráticos da escola pública, laica e gratuita: o relatório de Condorcet. In: Educ. Soc, Campinas, v. 24, n. 84, p. 735762 , set./2003. Disponível em: <http://www.scielo.br/scielo.php?pid=S010173302003000300002\&script=sci_arttext>. Acesso em: 20 jan. 2019.

BRASIL. Constituição da República Federativa do Brasil, de 25 de março de 1824. Manda observar a Constituição Politica do Imperio, offerecida e jurada por Sua Magestade o Imperador. Disponível em: 
<http://www.planalto.gov.br/ccivil_03/Constituicao/Constituicao24.htm> Acesso em: 24. fev. 2019.

Lei de 15 de outubro de 1827. Manda crear escolas de primeiras letras em todas as cidades, villas e logares mais populosos do Imperio. Disponível em: $<$ https://www2.camara.leg.br/legin/fed/lei_sn/1824-1899/lei-38398-15-outubro-1827566692-publicacaooriginal-90222-pl.html>. Acesso em 17. mar. 2019.

1934. Constituição da República Federativa do Brasil. Brasília, de 16 de julho de mar. 2019.

Decreto-lei $N^{o}$ 4.048, de 22 de janeiro de 1942. Cria o Serviço Nacional de Aprendizagem dos Industriários (SENAI) Disponível em: <http://www.planalto.gov.br/ccivil_03/Decreto-Lei/1937-1946/Del4048.htm>. Acesso em: 13 mar. 2019.

Decreto-lei $N^{o} 8.621$ de 10 de janeiro de 1946. Dispõe sobre a criação do Serviço Nacional de Aprendizagem Comercial e dá outras providências. Disponível em: <http://www.planalto.gov.br/ccivil_03/Decreto-Lei/1937-1946/Del8621.htm>. Acesso em: 13 mar. 2019.

Constituição da República Federativa do Brasil. Brasília, de 05 de outubro de 1988. Disponível em: <http://www.planalto.gov.br/ccivil_03/constituicao/constituicao.htm>. Acesso em: 23 fev. 2019.

Lei de Diretrizes e Bases da Educação Nacional (Lei $n^{o}$ 9394/96) de 20 de dezembro de 1996. Estabelece as diretrizes e bases da educação nacional. Disponível em: <https://presrepublica.jusbrasil.com.br/legislacao/109224/lei-de-diretrizes-e-baseslei-9394-96>. Acesso em: 13 abr. 2019.

Diretrizes Curriculares Nacionais para Educação Básica. Brasília, 2013. Disponível em: <http://portal.mec.gov.br/docman/julho-2013-pdf/13677-diretrizeseducacao-basica-2013-pdf/file>. Acesso em: 19 jan.2019.

CASTRO, Alba Tereza Barroso de. Estudantes de cotas: um convite à reflexão. In: Revista Virtual Textos \& Contextos, Rio Grande do Sul, v. 5, n. 1, p. 1-14, nov./2006. Disponível em: <file:///C:/Users/Leandro/Downloads/1020-3726-2-PB.pdf> Acesso em: 23 jan. 2019.

GALEANO, Eduardo. As veias abertas da América Latina. 46. ed. Rio de Janeiro: Paz e Terra, 2007. 
MILET, Rosa Maria Lepak. A orientação educacional que ultrapassa os muros da escola. 224 fls Dissertação (Mestrado em Educação). Fundação Getúlio Vargas, Rio de Janeiro, 1990.

PATTO, Maria Helena Souza. O fracasso escolar como objeto de estudo: anotações sobre as características de um discurso. In: Caderno de Pesquisa. São Paulo, s/v, n. 65, p. 72-77, maio, 1988. Disponível em <http://publicacoes.fcc.org.br/ojs/index.php/cp/article/view/1198/1204>. Acesso em: 06 fev.2019.

Maria Helena Souza. A produção do fracasso escolar: histórias de submissão e rebeldia. São Paulo: Casa do Psicólogo. 1999.

PNUD. Relatório do Desenvolvimento Humano: sustentar o progresso humano-reduzir as vulnerabilidades e reforçar a resiliência. 2014.

Panorama general Informe sobre Desarrollo Humano 2019 Más allá del ingreso, más allá de los promedios, más allá del presente: desigualdades del desarrollo humano en el siglo XXI 2019. Disponível em: <http://hdr.undp.org/sites/default/files/hdr_2019_overview_-_spanish.pdf $>$. Acesso em: 13 mar. 2019.

ROUSSEAU, Jean-Jacques. A origem das desigualdades entre os homens. São Paulo: Editora Escala, s/d.

. Emílio ou da educação. 3. ed. Rio de Janeiro: Bertrand, 1995.

UNESCO. Declaração Mundial sobre Educação para Todos: satisfação das necessidades básicas de aprendizagem. Jomtien, 1993. Disponível em: http://unesdoc.unesco.org/images/0008/000862/086291por.pdf>. Acesso em: 04 jan. 2019.

Recebido em: 17/10/2019

Aprovado em: 19/12/2019 